\title{
СТРУКТУРНО-СОДЕРЖАТЕЛЬНАЯ ХАРАКТЕРИСТИКА ПОНЯТИЯ «ФУНКЦИОНАЛЬНОЕ ЧТЕНИЕ», ЕГО СОЦИАЛЬНЬЕ ФУНКЦИИ В СОВРЕМЕННОМ ОБЩЕСТВЕ
}

\section{STRUCTURAL AND CONTENT CHARACTERISTICS OF THE CONCEPT OF "FUNCTIONAL READING", IT'S SOCIAL FUNCTIONS IN MODERN SOCIETY}

\section{A. Borshevskaya}

Summary: The article describes the concept of "functional reading", its social functions in modern society. The features of reading as one of the methods of obtaining and processing information are revealed. The main stages of the formation of functional reading are listed, as well as the forms of tasks that can be used in the lessons in primary school. Functional reading contributes to the development of erudition, research interest, search, self-control, and the overall development of intelligence in primary school children. The general concept of social intelligence, as well as the features of this phenomenon in primary school children, is characterized. Social intelligence plays an important role in the life of society and the individual, so its formation in children should be paid attention from an early age. An empirical study was organized to investigate the initial level of social intelligence formation, as well as the possibility of its development with the help of functional reading.

Keywords: functional reading, social intelligence, primary school students, modern society, social functions.

\author{
Борщевская Анастасия Юрьевна \\ учитель, ГБОУ Школа 1619 имени М.И. Цветаевой, \\ г. Москва; аспирант, Московский городской \\ педагогический университет \\ anastasia7608@mail.ru
}

Аннотация: В статье охарактеризовано понятие «функциональное чтение», его социальные функции в современном обществе. Раскрыты особенности чтения как одного из способов получения и обработки информации. Перечислены основные этапы формирования функционального чтения, а также формы заданий, которые возможно использовать на уроках в младшей школе. Описано то, как функциональное чтение способствует развитию эрудиции, исследовательского интереса, поиска, самоконтроля, общему развитию интеллекта у учащихся начальной школы. Охарактеризовано общее понятие социального интеллекта, а также особенности данного явления у младших школьников. Социальный интеллект играет большую роль в жизни общества и личности, поэтому его формированию у детей необходимо уделять внимание с ранних лет. Организовано эмпирическое исследование, направленное на исследование исходного уровня сформированности социального интеллекта, а также возможности его развития с помощью функционального чтения.

Ключевые слова: функциональное чтение, социальный интеллект, младшие школьники, современное общество, социальные функции.

Задачами обучения чтению в начальной школе являются:

- обучение навыкам правильного, беглого, выразительного и осознанного чтения;

- приобщение школьников к чтению и пониманию художественной литературы, правильному восприятию её образов и идейного содержания;

- расширение кругозора учащихся об окружающем мире, о жизни общества, воспитание культурных и литературных вкусов на лучших образцах мировой литературы;

- обогащение словаря школьников, развитие синтаксического строя их речи, обогащение фразеологии [6].

Чтение - процесс перекодирования графического текста в смысловые единицы, без звукового оформления или в звуковую речь и её понимание.

Д.Б. Эльконин называет чтение процессом воссоздания звуковой формы слова через её графическую составляющую [7].
По словам Е.Л. Гончаровой, чтение - деятельность, направленная на понимание авторского замысла, который передаётся в тексте с помощью лингвистического кода в тексте. Читательская деятельность - это осуществление читательской компетентности. Читательская компетентность - это любая читательская деятельность. Оба этих 
понятия являются системно-деятельностными объектами [3].

Чтение имеет тесную связь с актом устной речи. При чтении употребляются средства выразительности речи, связная речь передаёт содержание текста и способствует общению между читателями. Устная речь вырабатывает выразительность чтения. В методике выделяют четыре качества чтения: правильность, скорость, выразительность и понимание.

Целью функционального чтения является поиск информации для разрешения определённой задачи. Функциональное чтение способствует овладению следующими навыками:

- поиск информации;

- понимание прочитанного;

- работа с полученной информацией;

- применение информации для решения своей задачи $[6$, с. 6].

Функциональное чтение помогает не просто прочитать информацию, но и работать с ней, легче воспринимать смысл. Такое понимание положительно влияет не только на речевые навыки учащихся, но и на коммуникативные, что способствует развитию эмоционального и социального интеллекта.

Функциональное чтение учит пониманию смысла прочитанного, а также возможности применения полученной информации на практике. Процесс такого чтения необходимо разделить на несколько этапов: восприятие, истолкование, оценка возможности применения для решения конкретных задач.

Этап восприятия знакомит младшего школьника с искусством слова. Для ознакомления и для лучшего восприятия новой информации всегда лучше использовать средства наглядности, ИКТ и медиатехнологии, элементы игры и т. д., например, прослушивание различных аудиозаписей фрагментов художественного произведения, дополнение словесного ряда зрительным и образным рядом.

На первом этапе, этапе восприятия учитель привлекает и фиксирует внимание учащихся. На уроке можно поговорить о том, что у детей вызывает радостное настроение, о красоте природы. Например, музыка способствует созданию необходимого настроения у детей. Используя интонирование текста, дети могут придумать ритм и тональность произведения, а само музыкальное сопровождение будет аккомпанировать детскому исполнению стихов.

Важную роль играет мотивация, важно заинтересовать учащихся в исследовании текста, чтобы они могли прочувствовать глубину художественной речи. При этом нужно делать акцент именно на слове, а все остальные средства должны служить прикладную роль. Если у детей на первом этапе восприятия возникнет заинтересованность, то можно перейти к следующему этапу, а именно истолкованию текста.

Этап истолкования текста должен начинаться с простого анализа текста, просмотра иллюстраций. Дети выделяют в тексте ключевые слова, находят цитаты, отвечающие вопросам урока, находят отрывки в тексте, соответствующие иллюстрациям [4].

Необходимо также добавить пояснение непонятных эпизодов, краткий и корректный пересказ прочитанного, если ученики это свободно делают, это значит, что они уже перешли на новую ступень читательского умения и теперь можно перейти к последнему этапу.

Заключительный этап работы с текстом - проведение оценки прочитанного, который может быть сотворчеством детей и автора прочитанного произведения. Ученики могут придумать свою концовку или продолжение прочитанной истории, высказать своё отношение к прочитанному, свою общественную позицию, как бы он поступил в какой-либо ситуации из произведения, понять его смысл. И самое важное - понять, что прочитав какой-либо текст, они приобретают новый читательский опыт и теперь могут попытаться самостоятельно что-то сочинить.

Развитие навыков функционального чтения является важным умением для современного человека. Оно не только учит пониманию и применению прочитанного в период образования, но прививает навыки, которыми он будет пользоваться всю жизнь.

Главная задача функционального чтения заключается в правильном использовании современных методов, здесь важна систематическая работа, контроль и корректировка действий учащихся при обучении функциональному чтению, которые помогут развитию и формированию самодостаточной личности.

При функциональном чтении применяются также приёмы просмотрового и аналитического чтения, т.е. выделение ключевых слов, выбор цитат, анализ текста, составление и чтение схем, графиков, таблиц. Функциональное чтение - составляющая функциональной грамотности, т.е. способности человека использовать навыки чтения и письма в условиях социальной среды. Например, к такой грамотности можно отнести оформление счёта в банке, прочтение и выполнение инструкции, заполнение анкеты обратной связи и т.д.

Функциональная грамотность способствует успешному взаимодействию с социумом, то есть это тот уровень грамотности, который позволяет человеку вступать 
в отношения с внешней средой и максимально быстро адаптироваться и функционировать в ней, функциональная грамотность развивает социальный интеллект (СИ).

Коммуникативное и социальное развитие личности младшего школьника - это важная составляющая современного начального образования. Проблема формирования СИ одна из задач современной педагогики. Важно, чтобы ребёнок с ранних лет мог адаптироваться в обществе.

Одной из необходимых составляющих успешной социализации человека, становления его как специалиста практически любой сферы деятельности, способного быть организатором и участником работы современных коммуникативных систем является СИ.

Термин «социальный интеллект» был определён американским психологом Эдвардом Ли Торндайком. Именно СИ представляет собой индивидуально-психологическую особенность личности, он непосредственно влияет на межличностное взаимодействие. СИ, в отличие абстрактного и технического, отвечает за коммуникативность и способность находить общий язык между людьми,

В России впервые данное понятие было подробно изучено социологом и психологом М.Й. Бобнёвой [2]. Она определила, что общий уровень интеллекта не связан с СИ напрямую - общий интеллект может превышать социальный, но не гарантирует высокого его развития и не может заменить его. Процесс развития коммуникабельности способствует самореализации, формирования самодостаточности личности, что делает СИ предметом исследования психологической науки.

Психологи Н.В. Бачманова и Н.А. Стафурина считают, что развитие СИ помогает решать практически любые задачи на общение и раскрывает талант общения. Талант общения включает ряд особенностей, которые способствуют успешному развитию СИ:

1. Понимание качеств и особенностей человека, интуиция.

2. Наблюдательность и быстрая адекватная реакция на ситуацию и т.д.

3. Способность сопереживания, доброго и уважительного отношения к человеку, готовность прийти на помощь.

4. Способность оценки своего поведения (рефлексия).

5. Умение контролировать себя, свои чувства и эмоции в процессе общения (самоконтроль) [1].

Нормальное развитие СИ позволяет постоянно совершенствоваться, быстро адаптироваться к изменяющимся условиям, лучше понимать партнера по взаимодействию и общению, прогнозируя его и своё поведение.
Дэниел Гоулман, американский психолог и журналист, один из известных современных исследователей данного явления, автор книги «Social Intelligence», описывает его как умение «соображать, что к чему в отношениях».

Гоулман определяет две основные составляющие СИ:

- социальное восприятие - это то, как мы понимаем окружающих;

- социальные способности - это то, как мы реагируем на эти новые знания.

Все свойства обусловливают прогнозирование развития межличностных ситуаций, интерпретацию информации и поведения, готовность к социальному взаимодействию и принятию решений [8].

В.Н. Куницына [5] выделяет четыре основных признака развитого СИ:

1. Коммуникативно-личностный потенциал - навыки межличностного общения.

2. Основы самосознания: самоуважение, свобода мышления, открытость новым идеям.

3. Воображение, мышление: способность к пониманию и моделированию социальных явлений, и влияющих на них мотивов.

4. Энергетические характеристики: выносливость, активность, стрессоустойчивость.

Учёные-педагоги Л.С. Выготский, П.П. Блонский, А.Н. Леонтьев, С.Л. Рубинштейн, Д.Б. Эльконин и многие др. придавали большое значение пониманию возрастных особенностей развития личности. Учёные указывали, что возраст влияет на поведение в определённые жизненные периоды, что младший школьный возраст является наиболее благоприятным для становления и развития отдельных видов способностей. Психологи также советуют наблюдать за другими людьми, за теми, у кого хорошо развит СИ, внимательно относиться к собеседникам, что помогает лучше их понять. Эксперты советуют активное слушание - внимательно следить за нитью разговора, переспрашивать, если мысль не ясна.

Кроме того, исследователи в области педагогики и психологии советуют развивать эмоциональный интеллект. Следить можно за собственными эмоциями и за тем, как меняется общение с другими в зависимости от настроения - полезный навык в любой ситуации.

На основании авторитетных мнений можно утверждать о необходимости развития СИ с позиции возрастного подхода, что является весьма перспективным. Младший школьный возраст является стартом для начала обучения функциональному чтению, поэтому данная методика возможна к реализации с целью развития СИ в рамках возрастного подхода. 
Для исследования проблемы формирования СИ у учащихся начальной школы было проведено эмпирическое исследование, которое проходило в несколько этапов:

1. Диагностический или констатирующий этап, который включает в себя такие диагностические методики: тест на определение уровня СИ и задания для проверки техники чтения и понимание прочитанного.

2. Формирующий этап заключается в использовании комплекса заданий с применением функционального чтения для формирования СИ. На этом этапе разработана модель развития СИ у младших школьников посредством функционального чтения (табл. 1).

3. Контрольный этап или оценочный, который состоит в повторном применении методик из констатирующего этапа для того, чтобы проследить динамику развития СИ у младших школьников.

В исследовании приняли участие 30 учащихся младшей школы.

Цель исследования: изучить психолого-педагогические условия развития социального интеллекта в младшем школьном возрасте.

\section{Задачи}

- обозначить условия формирования социального интеллекта у младших школьников;

- сформировать социальный интеллект у детей младшего школьного возраста методом функционального чтения.

Методы: тестирование, наблюдение, беседа с детьми, игра, обследование предметов.

\section{Констатирующий этап}

Цель: установить уровень развития социального интеллекта у младших школьников.

Тест на определение уровня социального интеллекта проводился в игровой форме, так как, именно такой формат является более актуальным и понятным для младших школьников.

1. Мне нравится общаться с людьми.

$$
\text { Да - Нет - Не знаю }
$$

2. Я легко завожу друзей.

$$
\text { Да - Нет - Не знаю }
$$

3. Всегда готов/а прийти на помощь.

Да - Нет - Не знаю

4. Я всегда с лёгкостью угадываю чувства другого человека.

Да - Нет - Не знаю

5. Мне нравится заводить новые знакомства.

Да - Нет - Не знаю

6. Мне легко общаться как со сверстниками, так и взрослыми.

Да - Нет - Не знаю

7. Мне нравится придумывать разные игры и интересные занятия.

Да - Нет - Не знаю

8. Я предпочитаю учиться в компании, чем в одиночку. Да - Нет - Не знаю

9. Мне не нравится, когда с кем-то поступают несправедливо.

Да - Нет - Не знаю

10. Я всегда стараюсь поступать честно в отношениях с другими людьми.

Да - Нет - Не знаю

Результаты оценивались по количеству положительных и отрицательных вариантов на вопросы. Необходимо было установить насколько ребёнок умеет общаться, заводить знакомства, адаптироваться в обществе, что будет способствовать личностному росту, снижению количества конфликтов среди школьников. Ответ «да»1 б.; нет - 0,5; не знаю - 0 баллов.

Высокий уровень (8 -- 10 б.) - ребёнок охотно идёт на контакт, поддерживает хорошие отношения в своём классе, имеет много друзей и знакомых. Обладает такими качествами как: отзывчивость, понимание, проявляет интерес к понятиям честности и справедливости.

Средний уровень (5 - 7 б.) - ребёнок не очень охотно идёт на контакт, не очень любит общаться, имеет немного друзей, не очень разбирается в настроении других людей.

Низкий уровень (0 - 4 б.) - ребёнок выражает полное безразличие или же враждебность к окружающим людям. Наблюдается отсутствие интереса к общению, у такого респондента нет друзей, ему трудно установить контакт.

Для подведения итогов первого этапа важно определять психотип детей: экстраверт, интроверт или амбиверт. Данный момент очень важен, так как, интроверты не очень общительны, но это не значит, что они всегда обладают низким социальным интеллектом. Социальный интеллект заключается, по большей мере, во взаимопонимании, отзывчивости детей, чем в высокой потребности к общению.

Высокий уровень - 6 чел. (20\%) 
Средний уровень - 10 чел. (33,33\%)

Низкий уровень - 14 чел. (46,67 \%)

Далее была сформирована модель развития социального интеллекта у младших школьников посредством функционального чтения.

Таблица 1.

Модель развития социального интеллекта у младших школьников посредством функционального чтения

\begin{tabular}{|c|c|c|}
\hline Этапы & Методы & Результаты \\
\hline Восприятие & $\begin{array}{l}\text { Просмотр фрагментов } \\
\text { мультфильма «Конёк- } \\
\text { горбунок». }\end{array}$ & $\begin{array}{l}\text { формируется наблюда- } \\
\text { тельность, понимание }\end{array}$ \\
\hline Истолкование & $\begin{array}{l}\text { Дети ищут увиденные } \\
\text { эпизоды в книге, зачиты- } \\
\text { вают его с соответствую- } \\
\text { щей интонацией, а после } \\
\text { поясняют прочитанное, } \\
\text { находят лексические } \\
\text { средства в тексте и по- } \\
\text { ясняют их функции. }\end{array}$ & $\begin{array}{l}\text { - формируется по- } \\
\text { нимание увиденного и } \\
\text { прочитанное; } \\
\text { - ассоциативное мыш- } \\
\text { ление; } \\
\text { - дети умеют определять } \\
\text { эмоциональное состояние } \\
\text { героев; } \\
\text { - учащиеся стараются } \\
\text { выделить, что именно } \\
\text { имел ввиду автор произ- } \\
\text { ведения; } \\
\text { - формируется чувство } \\
\text { справедливости и поня- } \\
\text { тие о настоящей дружбе. }\end{array}$ \\
\hline Оценка & $\begin{array}{l}\text { Учащиеся дают оценку } \\
\text { действиям героев, а так- } \\
\text { же пишут свои варианты } \\
\text { развития событий или } \\
\text { решения героев }\end{array}$ & $\begin{array}{l}\text { формируется способ- } \\
\text { ность оценить ситуацию } \\
\text { и поведение человека в } \\
\text { определённых обстоя- } \\
\text { тельствах, интуиция }\end{array}$ \\
\hline
\end{tabular}

На контрольном этапе были использованы повторно те же методики, что и на констатирующем. Результаты работы:

Высокий уровень - 8 чел. (26,67\%)

Средний уровень - 15 чел. (50\%)

Низкий уровень - 7 чел. (23,33\%)

Контрольный этап сформированности СИ у учащихся младших классов, показал динамику в изменении результатов исследования, по сравнению с первоначальным уровнем, мы имеем значительное повышение результатов.

На констатирующем этапе преобладает низкий уровень - 46, 67 \%, на контрольном этапе - средний уровень (50\%). Иными словами, работа, организованная с использованием функционального чтения, активизирует у учащихся различные мыслительные операции, размышления и наблюдательности.

Школьная практика показывает, что младшие школьники с помощью функционального чтения понимают смысл произведения по-разному. Во время урока литературы с помощью функционального чтения формируется свободное самовыражение, изложению разных точек зрения, позиция читателя, моделируется поведение.

Полученные данные показывают, что лучшей социальной адаптации необходимо развивать СИ уже с начальной школы, в этом возрасте дети больше стремятся к общению, они более открыты для развития. Результаты контрольной диагностики подтвердили достоверность выдвинутой нами гипотезы о том, что развитие навыка СИ будет происходить более успешно, если в процессе данной работы будут использованы этапы функционального чтения.

\section{ЛИТЕРАТУРА}

1. Бачманова Н.В. К вопросу о профессиональных способностях психолога / Н.В. Бачманова Н.А. Стафурина // Современные психолого-педагогические проблемы высшей школы. - Вып. 5. - Л., 1985

2. Бобнёва М.Й., Техническая психология. Москва: изд-во: Наука, 1966, 128 с

3. Гончарова Е.Л. Ранние этапы становления читательской деятельности при норме и при отклонениях в развитии: автореф. дис. доктора псих. наук: 19.00.10. - М.: 2009. -40 c.

4. Гросс И.С. Функциональное чтение и работа с текстом как одно из направлений работы с учащимися в условиях ФГоС // Школьная педагогика. - 2018. № 3 (13). - C. 15-17.

5. Куницына, В.Н. Социальная компетентность и социальный интеллект: структура, функции, взаимоотношение / В.Н. Куницына // Теоретические и прикладные вопросы психологии. - СПб., 1995. - С. 48-61

6. Низенькова М.Г. Функциональное чтение // Разбираемся в терминологии. Чтение: смысловое, продуктивное, функциональное. - М.: Корпорация «Российский учебник», 2019. - С. 6

7. Эльконин Д.Б. Как научить детей читать: Избранные психологические труды. - М.: Изд-во «Институт практической психологии», Воронеж: НПО «МОДЭК», 1997. - C. 323-349

8. Goleman D. Social intelligence: the new science of human relationships. Author: Daniel Golemanr. - N.Y.: Bantam Books, 2007. - 403 p.

(с) Борщевская Анастасия Юрьевна (anastasia7608@mail.ru). 